\title{
Outcomes of Anal Sphincter Injury Repair; Minia University Hospital Experience Prospective Study
}

\author{
Doaa A. Saad and Amr A. Elhiny \\ General Surgery Department, Faculty of Medicine, Minia University, Egypt, 6111
}

\begin{abstract}
Aim: Test the effectiveness and results of anal sphincter repair and the effect of different factors on the outcomes of the operation. Patients and methods: In the period between January 2017 and January 2020; thirty Patients who had fecal incontinence and who presented to Minia University hospital underwent anal sphincter repair. Data on demographic information, etiology, duration of symptoms before surgery, imaging data, type of procedure performed, complications, and outcomes were collected. The participants were followed-up for a minimum of 6 months following anal sphincter repair. Patients were classified according to their satisfaction from surgery into two groups; well satisfied and not satisfied patients. They were classified according to the degree of continence after surgery into full; partial and non-continent patients. Results: $83.3 \%$ of patients were satisfied after surgery versus $16.7 \%$ who were unsatisfied. About seventy-three percent $(73.3 \%)$ of the 30 patients stated subjectively that they had become fully continent after the repair, however, 8 patients $(26.7 \%)$ became partially continent. Conclusion: Sphincter repair operation is a safe and feasible operation for the treatment of fecal incontinence due to different causes. Sphincter injuries due to road traffic accidents are associated with best outcomes while iatrogenic injuries have the worst outcomes. Better results are obtained with external sphincter repair versus the isolated internal sphincter repair. It seems that age and duration after surgery don't affect the outcomes.

Keywords: Feacal incontinence. Anal sphincter injury. Incontinence. Anal sphincteroplasty

Author contributions the authors had substantial contributions to the design of the work; the acquisition, analysis, or interpretation of data of the work done by Dr Amr Elhiny; Dr Doaa Ali revised the work critically for important intellectual content and approve the version to be published.
\end{abstract}

\section{Introduction}

Fecal incontinence (FI) is defined as involuntary loss of flatus, liquid stool or solid stool ${ }^{[1]}$. FI has devastating impacts on quality of life $^{[2]}$. FI can result from anal sphincter defects which can involve the external anal sphincter (EAS); the internal anal sphincter (IAS), or both muscles ${ }^{[3]}$. The etiology of these defects may be surgical, traumatic or obstetric causes ${ }^{[4]}$. Obstetric trauma is the most common cause of sphincteric lesions due to many factors such as use of forceps; breech presentation and episiotomy which results in neuropathic and mechanical injury to the pelvic floor ${ }^{[5,6]}$.

The diverse etiology of FI making its treatment a complex issue. Management of FI includes conservative; biofeedback or sur- gical treatment ${ }^{[7]}$. There is no standard surgical procedure for FI. Overlapping anal sphincter repair is the commonest surgical procedure $^{[8]}$. Anterior levatorplasty could be added to improve sphincter pressure of the anal canal by scar tissue formation and consequently leads to symptomatic improvement ${ }^{[7]}$.

Anterior sphincter repair achieves early improvement with success rates between 69 and 97 percent ${ }^{[9]}$. However, long-term results (69-120 months) have shown success rates ranging from 14 to 80 percent $^{[10]}$.This lower success rates may be attributed to aging with associated striated muscle atrophy or may be due to the occult coexistence of anatomical defects of the pelvic floor ${ }^{[11]}$. In obstetric lesions; the 
primary repair of sphincteric injuries, which detected at delivery, by suitably trained surgeon decreases the associated morbidity ${ }^{[12]}$. This study was designed to determine short and long-term outcomes in patients with FI.

\section{Patients and Methods}

This study is a prospective study aiming to describe changes in fecal incontinence symptom severity and patient satisfaction after surgical repair. it was done in Minia university hospital in the period between January 2017 and January 2020. Thirty Patients who had fecal incontinence and who presented to Minia University hospital were included, they subsequently underwent anal sphincter repair. All participants had a defect of the anal sphincters identified either by physical examination or endoanal ultrasound (Figure1) or MRI of the anal canal.

\section{Inclusion criteria:}

1- Sex: both sex were included;

2- Age: any age;

3- Patients fit for surgery;

4- Any cause of sphincter defects including iatrogenic; road traffic accidents or obstetric trauma.

\section{exclusion criteria:}

1- Un repairable defects: defects more than $50 \%$ of sphincter circumference or multiple defects.

2- Patients unwilling or unfit for surgery.

Data on demographic information, etiology, duration of symptoms before surgery, imaging data, type of procedure performed, complications and outcomes were collected. The participants were followed-up for a minimum of 6 months following anal sphincter repair. To assess what effect an increased length of time post-surgery upon results, the patients were categorized into those having short-term follow-up of less than one year and those having long-term follow-up more than one year post surgery.

Patients were classified according to their satisfaction from surgery into two groups; well satisfied and not satisfied patients. They were classified according to the degree of continence after surgery into full; partial and non-continent patients.
As regard the type of repair, patients were divided into two groups: those with external sphincter repair and those with isolated internal sphincter repair. As regard the etiology of sphincter injury; patients were classified into three categories: obstetric (Figure 2); traumatic (Figure 3); and iatrogenic sphincter injuries.

Outcomes were compared with respect to etiology, type of repair, duration of symptoms and duration of follow up to the degree of continence and patient satisfaction as the primary outcomes. Wound complications as a second outcome were evaluated in regards to type of wound closure. Wound complications as wound disruption; pain and other complications.

\section{Operative technique}

External anal sphincter repair was performed under spinal or general anesthesia with the patient in the dorsal lithotomy position. All patients had bowel preparation except in trauma patients. A curvilinear incision was made centered over the site of sphincter defect about one $\mathrm{cm}$ from the anal verge. The posterior vaginal wall was sharply dissected off of the perineal body. Diatheremy were used to dissect around the external anal sphincter for optimum mobilization (Figure 4). End to end repair or overlapping repair was performed by re-approximating the ends of the EAS muscle. The sphincter was sutured using2/ 0-prolene suture (Figure 5). The vaginal wall was repaired using vicryl $2 / 0$ absorbable suture. levatoplasty was performed when indicated, Levateroplasty had been done by identifying the puborectalis muscles anteriorly and approximating them with interrupted 2-0 non absorbable sutures. Internal sphincter repair was performed by identifying the inter-sphincter plane which was dissected enabling end to end repair of the internal anal sphincter. The wound was closed either vertically (Figure 6) or by closing the lateral edges of the wound and leaving the central part, in some cases, surgeons had used a diversion stoma. A urinary catheter was placed at the end of the procedure and removed after 48 hours.

Ethical approval the protocol of the study was discussed and approved regarding ethics of research in the general surgical depart-

Outcomes of Anal Sphincter Injury Repair; Minia University Hospital Experience Prospective Study 
ment. The study had been approved by the ethical committee for human studies in our institution. Full written, informed consent was signed from all participants.

Informed consent Informed consent was obtained from all their patients before the procedure was performed.

\section{Statistical Analysis}

The statistical program SPSS version 19 was used for data entry and analysis. Quantitative data were presented by mean and SD, whereas qualitative data were presented by frequency distribution. The Chi-square test was used to compare between two or more proportions. The Student's t test was used to compare two means. The lowest accepted level of significance was 0.05 or less.

\section{Results}

This study included 30 patients who had fecal incontinence and underwent anal sphincter repair either external or internal

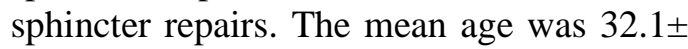
13.9. The duration of symptoms at the time of surgery was ranged from 0-60 months with a mean $20 \pm 19.6$. The mean follow up was $22.4 \pm 14.5$ months (Table1).

Obstetric trauma was the main cause of injury $(40 \%)$, followed by road traffic accidents $(33.3 \%)$ and the iatrogenic cause represents $(26.7 \%)$ of the cases. About $87 \%$ of patients underwent external repair and $13.3 \%$ underwent internal repair. The most common postoperative complication was wound disruption, which occurred in 14 patients $(46.7 \%)$. Superficial anal and rectovaginal fistula had occurred in three patients, perineal pain occurred in two patients and feacal impaction occurred in only one patient. Six patients $(20 \%)$ required colostomy. Table 2 show the clinical and operative characters of patients (Table2).

Table 3 showed that $83.3 \%$ of patients were satisfied after surgery versus $16.7 \%$ who were unsatisfied. About seventy-three percent $(73.3 \%)$ of the 30 patients stated subjectively that they had become fully continent after the repair, however, 8 patient (26.7\%) became partially continent (continent to feces but not to flatus) (Table 3).
Vertical skin suture was used in 20 patient $(66.7 \%)$ and lateral skin suture was performed in 10 patients $(33.3 \%)$. There was a significant difference between them as regards to postoperative wound disruption as $80 \%$ of patients with lateral skin suture had experienced postoperative wound disruption versus $30 \%$ of patients with vertical skin suture (Table 4).

In order to determine the impact of different factors on the outcomes after surgery, we perform analytic statistics between different factors and the degree of continence and patient satisfaction (Table 5\&6). The cause of injury to the sphincter was a significant factor in the final outcomes, all patients who experienced fecal incontinence due to trauma became fully continent. Whereas, patients who subjected to iatrogenic injury had the worst outcome as half of them was partially continent after surgery. And this difference was statistically significant $(p=0.04)$, this was the same in the degree of satisfaction as it was statistically better in trauma followed by obstetric followed by iatrogenic injuries $(\mathrm{p}=0.01)$.

Moreover, there was highly significant difference between those who underwent external and internal repair as regards to degree of continence and the degree of satisfaction ( $\mathrm{p}=0.02$ and 0.001 respectivelly) as $80.8 \%$ of patients who underwent external repair perceived complete continence after surgery versus only $25 \%$ of patients who underwent internal repair. There was no statistically significant difference in the level of continence between those with short or long term follow up. In the short term follow-up, patients' perception of incontinence compared to preoperative status revealed that $(66.7 \%)$ felt fully continent compared to $(77.8 \%)$ of those subjected to long term follow-up, however the difference was statistically significant in the satisfaction as in the short follow up; $66.7 \%$ of patients were satisfied compared to $94.4 \%$ of those subjected to long term follow-up $(p=0.04)$. Duration of symptoms before operation was not a significant difference in the outcomes of surgery either continence nor satisfaction $(\mathrm{p}=0.07 \& 0.3)$ respectively. 
Table 1: Baseline characteristics of patients undergoing anal sphincter repair

\begin{tabular}{|l|c|}
\hline Baseline characteristics & \\
\hline Age (years) & $2-55$ \\
Range & $32.1 \pm 13.9$ \\
mean \pm SD & $18(60 \%)$ \\
\hline Sex & $12(40 \%)$ \\
Female & \\
Male & $0-60$ \\
\hline Duration of symptoms (months) & $20 \pm 19.6$ \\
$\begin{array}{l}\text { Range } \\
\text { mean } \pm \text { SD }\end{array}$ & $6-48$ \\
\hline Follow up duration (months) & $22.4 \pm 14.5$ \\
Range & \\
mean \pm SD & \\
\hline
\end{tabular}

Table 2: Clinical and operative characteristics of patients undergoing anal sphincter repair

\begin{tabular}{|l|c|c|}
\hline Clinical and operative characteristics & No & \% \\
\hline Cause of injury & 12 & 40 \\
Obstetric & 10 & 33.3 \\
Trauma & 8 & 26.7 \\
Iatrogenic & 26 & 86.7 \\
\hline Type of operation & 4 & 13.3 \\
External repair & & 20 \\
Internal repair & 6 & 80 \\
\hline Colostomy & 24 & \\
Yes & 14 & 46.7 \\
No & 2 & 6.7 \\
\hline Postoperative complications & 2 & 6.7 \\
Wound disruption & 1 & 3.3 \\
Pain & 1 & 3.3 \\
Superficial anal fistula & 10 & 33.3 \\
Rectovaginal fistula & 18 & 60 \\
Feacal impaction & 2 & 6.7 \\
\hline Site of trauma & & 66.7 \\
Lateral & 20 & 33.3 \\
Anterior & 10 & 40 \\
Circumferential & 12 & 60 \\
\hline Type of skin suture & 18 & \\
Vertical & & \\
Lateral & & \\
\hline Follow up & & \\
Short less or equal one year & & \\
Long ore than one year & & \\
\hline
\end{tabular}


Table 3: Operative outcomes of patients undergoing anal sphincter repair

\begin{tabular}{|l|c|c|}
\hline \multicolumn{1}{|c|}{ Operative outcomes } & No & \% \\
\hline Degree of satisfaction & 4 & 13.3 \\
Not satisfied & 26 & 86.7 \\
Satisfied & 8 & 26.7 \\
\hline Continence & 22 & 73.3 \\
Partial & & \\
Complete & & \\
\hline
\end{tabular}

Table 4: Relation between type of skin suture and postoperative wound disruption:

\begin{tabular}{|l|c|c|c|}
\hline Wound disruption & \multicolumn{2}{|c|}{ Type of skin suture } & \multirow{2}{*}{ p value } \\
\hline & $\begin{array}{c}\text { Vertical } \\
\mathbf{n = 2 0}\end{array}$ & $\begin{array}{c}\text { Lateral } \\
\mathbf{n = 1 0}\end{array}$ & \\
\hline Yes & $6(30 \%)$ & $8(80 \%)$ & \multirow{2}{*}{$0.028^{*}$} \\
\hline No & $14(70 \%)$ & $2(20 \%)$ & \\
\hline
\end{tabular}

Table 5: Relation between degree of continence and operative characteristics:

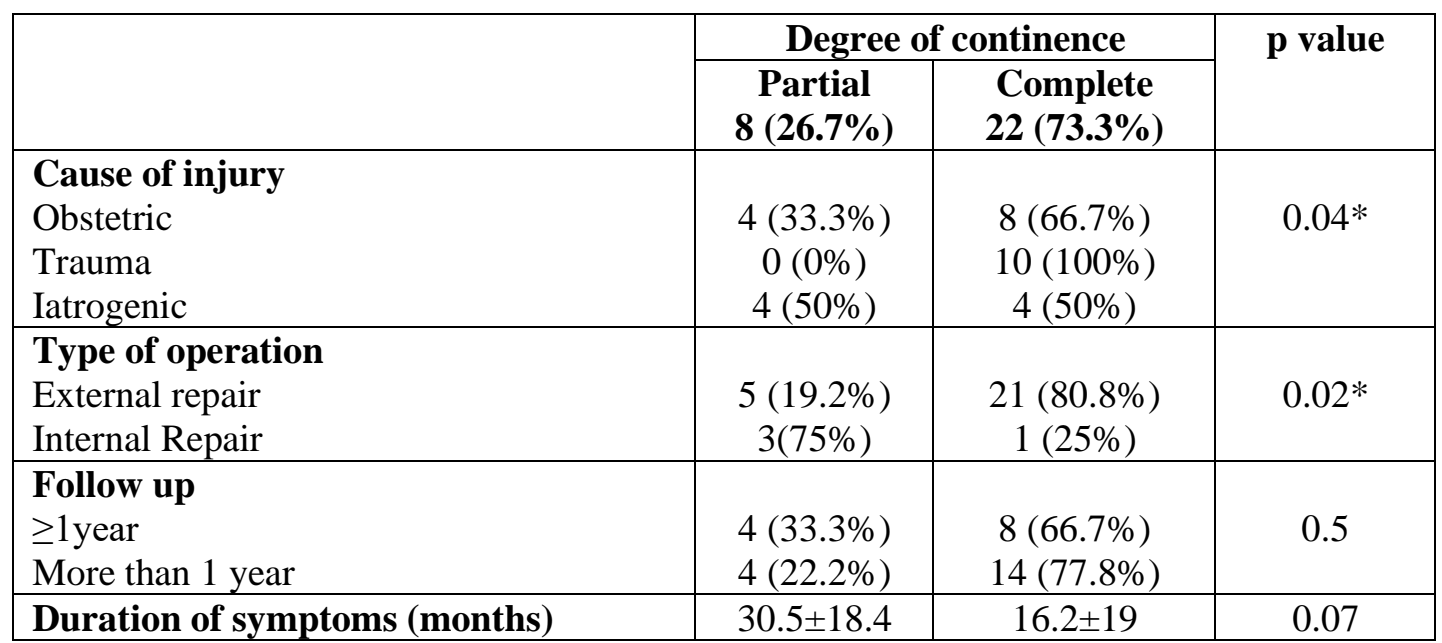

Table 6: Relation between patient satisfaction and operative characteristics:

\begin{tabular}{|c|c|c|c|}
\hline & \multicolumn{2}{|c|}{ Degree of satisfaction } & \multirow{2}{*}{ p value } \\
\hline & $\begin{array}{c}\text { Not satisfied } \\
5(16.7)\end{array}$ & $\begin{array}{l}\text { Satisfied } \\
25(83.3)\end{array}$ & \\
\hline $\begin{array}{l}\text { Cause of injury } \\
\text { Obstetric } \\
\text { Trauma } \\
\text { Iatrogenic }\end{array}$ & $\begin{array}{c}1(8.3 \%) \\
0(0 \%) \\
4(50 \%)\end{array}$ & $\begin{array}{c}11(91.7) \\
10(100) \\
4(50)\end{array}$ & $0.01 *$ \\
\hline $\begin{array}{l}\text { Type of operation } \\
\text { External repair } \\
\text { Internal Repair }\end{array}$ & $\begin{array}{l}2(7.7) \\
3(75)\end{array}$ & $\begin{array}{c}24(92.3) \\
1(25)\end{array}$ & $0.001 *$ \\
\hline $\begin{array}{l}\text { Degree of continence } \\
\text { Partial } \\
\text { Complete }\end{array}$ & $\begin{array}{c}3(37.5 \%) \\
2(9.1 \%) \\
\end{array}$ & $\begin{array}{c}5(62.5 \%) \\
20(90.9 \%) \\
\end{array}$ & 0.06 \\
\hline $\begin{array}{l}\text { Follow up } \\
\geq 1 \text { year } \\
\text { More than } 1 \text { year }\end{array}$ & $\begin{array}{c}4(33.3) \\
1(5.6)\end{array}$ & $\begin{array}{c}8(66.7) \\
17(94.4) \\
\end{array}$ & $0.04 *$ \\
\hline Duration of symptoms (months) & $25 \pm 26.6$ & $19.2 \pm 18.9$ & 0.3 \\
\hline
\end{tabular}


Figure legends:

Figure 1endo-anal ultrasound showing internal sphincter defect from 7 to 10 oclock Figure 2obstetric anal sphincter injury

Figure 3traumatic anal sphincter injury

Figure 4both ends of external anal sphincter mobilized

Figure 5overlapping anal sphincter repair repair

Figure 6.longitudinal closure of the wound

Figure 7 wound disruption

Figures:
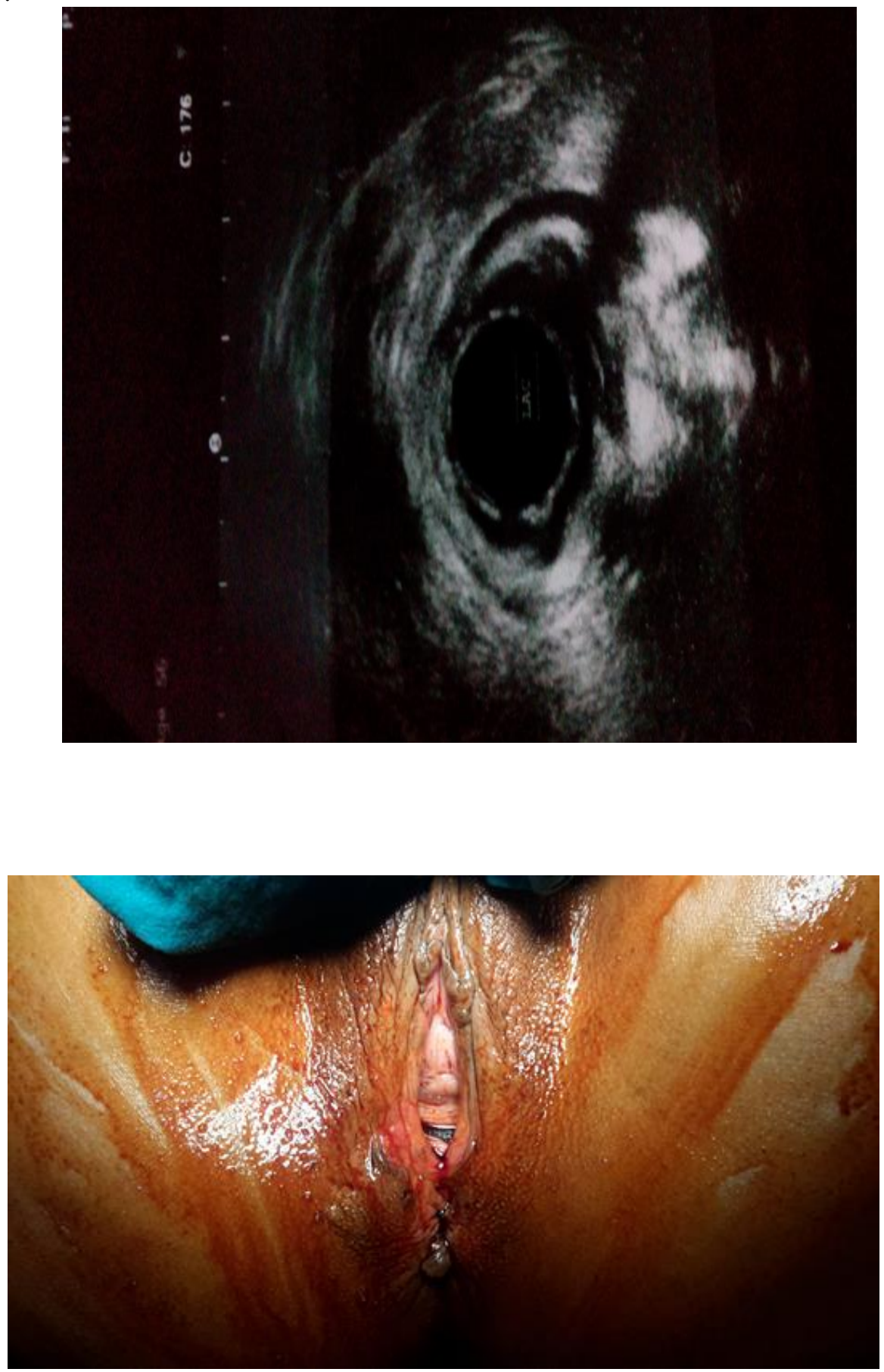

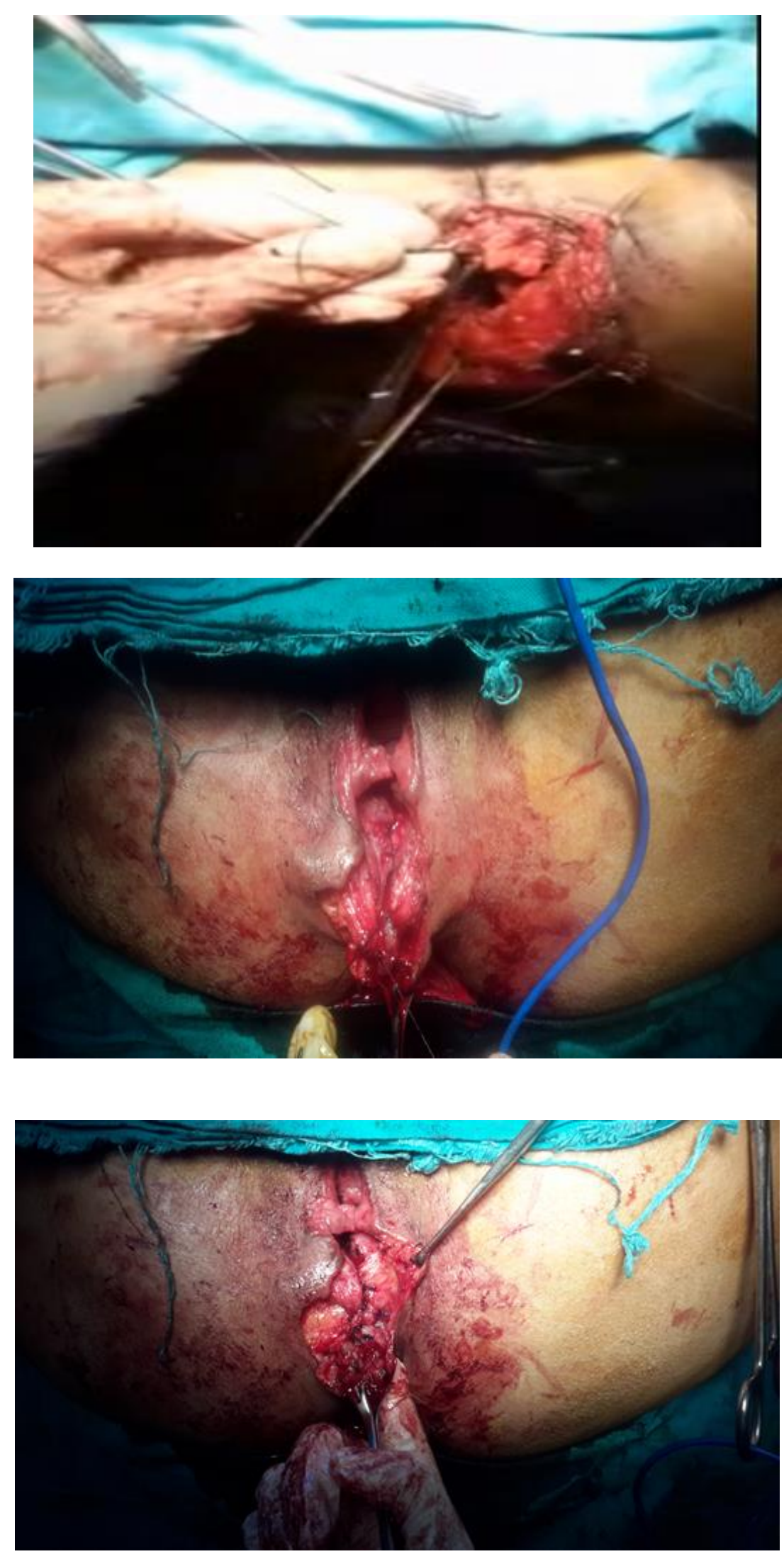

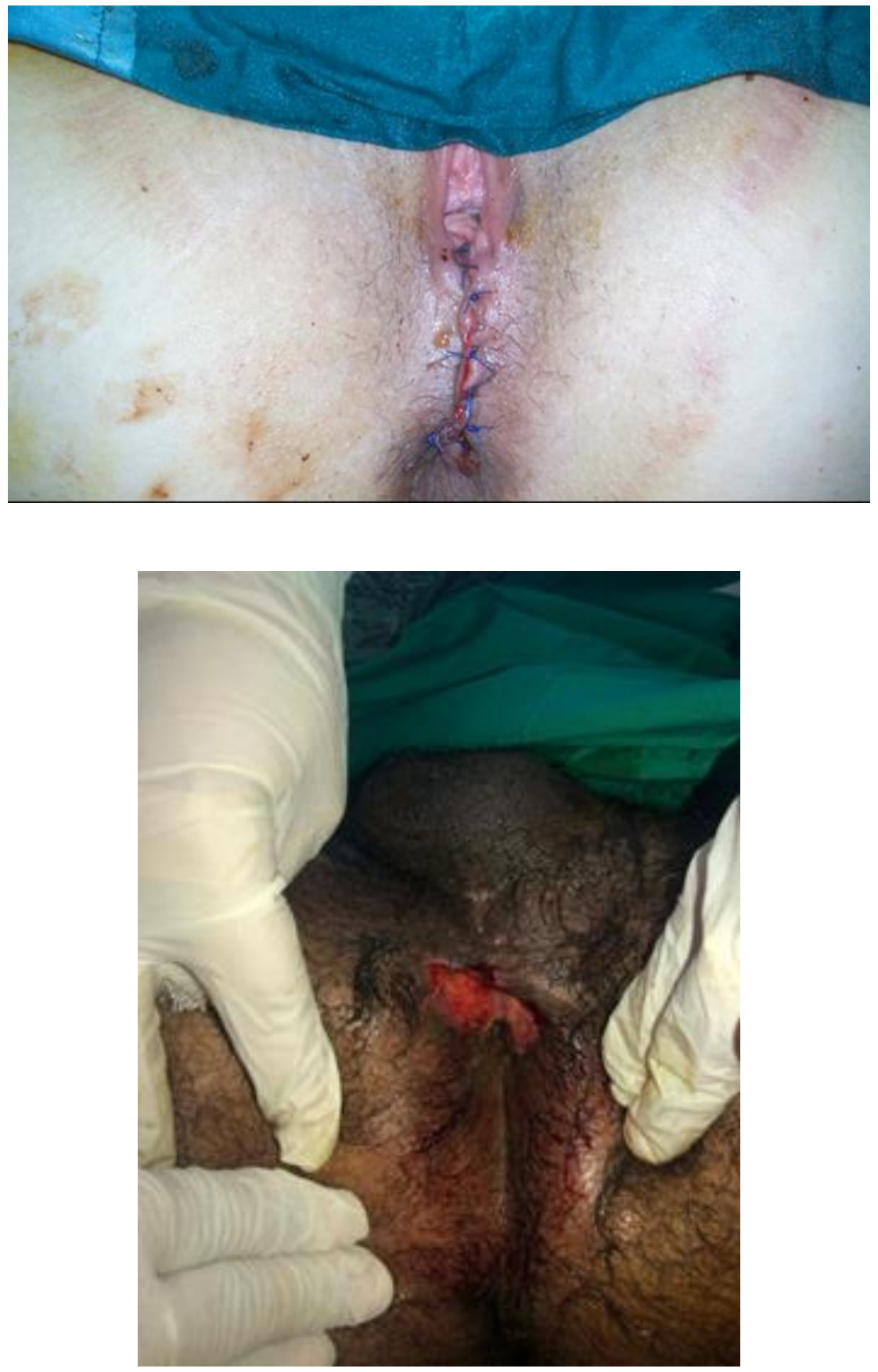

\section{Discussion}

This study is a prospective study to evaluate the outcomes of anal sphincter injury repair and the effect of different factors on the outcomes of surgery; primary outcomes in our study are the degree of continence and degree of satisfaction and secondary outcomes are post-operative complications.

Our study included thirty patients; their age ranged from 2 to 55 years with mean age of 32.1 year. Patients were divided in two age groups; young ( $<$ 40years) and older age groups ( $>40$ years); we found no statistically difference between the two-age group as regard the degree of continence. This is in consistent with other previous studies $^{[7,13,14,8]}$, however other studies found that older age results in a poor function as studies $^{[15-17]}$. One possible explanation for the poorer results in the elderly patients may be a neurogenic or myogenic component as well as structural sphincter defici ${ }^{\mathrm{t}}{ }^{[17]}$, Pudendal nerve terminal motor latency 
(PNTML) was considered to be an important factor in explanation of the poor outcomes after repair as it was recognized by Tjandra et al., ${ }^{[18]}$. We examined the results of anal sphincter repair in 18 female and 12 male patients, as to our knowledge; few studies reported the results of sphincter repair in male patients, Parvez et. al., in a Cohort study of 29 patients with traumatic sphincter injury include 21 male patient; they concluded that road traffic accidents was the leading cause of anal injuries in male patients ${ }^{[19]}$. In our study road traffic accidents were also the commonest cause of sphincter injuries in males followed by iatrogenic injuries. Subjectively; $77.3 \%$ of our patients had complete continence after surgery while $26.7 \%$ of patients had partial incontinence after surgery, $86.6 \%$ were satisfied by the results of the operation and $13.3 \%$ were unsatisfied, these results were nearly similar to the results of previous studies $^{[20,7,21,12]}$.

Obstetric trauma was the main cause of injury $(40 \%)$, followed by road traffic accidents $(33.3 \%)$ and the iatrogenic cause represents $(26.7 \%)$ of the cases, this is comparable with previous studies as Fang et. Al who reported $54 \%$ and Pezim et. al., who reported $58 \%{ }^{[22,23]}$. All patients have injuries due to traffic accidents became fully continent after surgery. Whereas patients who subjected to iatrogenic injuries had the worst outcome as half of them was partially continent after surgery. And this difference was statistically significant $(p=0.04)$. the same occurred with the degree of satisfaction where $50 \%$ of iatrogenic injuries patients were unsatisfied while only $8 \%$ of obstetric injuries were unsatisfied and the difference was significant. Sezai et al., in his study compare the results of sphincter repair in obstetric and none obstetric injuries and found significantly better post-operative manometric results in the non-obstetric group also Patient satisfaction was slightly better in the non-obstetric group; and this is in consistence with our study ${ }^{[12]}$. Ha et al., also reported that there was better continence in patients with non-obstetric compared with obstetric injury, although this did not show statistical significance ${ }^{[24]}$. Rothbarth et. al., concluded that results of sphincter repair because of obstetric injury are considered to be worse than in patients having sphincter repair with other causes ${ }^{[25]}$. high incidence of pudendal nerve damage in these patients might be the cause ${ }^{[26]}$. But Londono et. al., in his study founded the cause of injury to the sphincter was not a significant factor in the final outcomes ${ }^{[27]}$.

As regard the type of repair we had two groups; external sphincter repair performed in 26/30 patients while isolated internal sphincter repair was performed in 4/30 patients, poor results in the group of internal sphincter repair were noted as only one patient had post-operative complete continence and only one patient was satisfied. This was also reported by Leroi et al. who reported the results of IAS repair alone in five patients with fecal incontinence; no patient of them achieved full continence and the overall postoperative clinical, manometric, and radiological findings were disappointing ${ }^{[28]}$. Oberwalder et al., com-pared combined versus external sphincter repair and found no statistically significant difference between the two groups ${ }^{[3]}$. The mean duration of follow up in our study was $22.4 \pm 14.5$ months, we divided patients into two groups; short follow up duration which include patients of less than one year follow up; and long term follow up of more than one year to test the effect of duration on continence and satisfaction. In the shortterm follow-up $66.7 \%$ of patients were fully continent compared to $77.8 \%$ in the long term follow-up. There was statis-tically significant improvement in the degree of satisfaction in the long follow up.. this is in consistence with the study of. Evans et. al., who reported no difference in the levels of continence between those with short- or long-term follow-up ${ }^{[7]}$.--- also found only a slight deterioration from short-term results in his study at a median of 7 years follow $u^{[21]}$. Short- and medium-term improvements in FI have been previously reported after EAS repair to be as high as $86 \%^{[8]}$. However in other longer term follow up studies they have reported outcomes after EAS repair ranging from $14 \%$ to $80 \%$ of subjects $^{[10,29,30]}$. This large range may be a result of different primary outcomes and the definitions of treatment success or different 
patient populations ${ }^{[8]}$. As regard post-operative wound complications; we found that wound disruption was the most common complication occurred in 14/30(46\%) and managed conservatively (Fig.7), peri-anal pain occurred in two patients, superficial anal fistula occurred also in two patients, recto-vaginal fistula occurred in one patient and managed surgically while feacal impaction occurred in one patient and managed by disimpaction under general anesthesia. Schimmer et. al., in his paper found that the most frequent early complication was wound infection in $(15.6 \%)$ of cases, impaction occurred in 9 patients and led to breakdown of the repair in 1 , two patients developed a haematoma and 1 developed cellulitis. Late complications occurred in $(9.3 \%)$ of cases; the most frequent were recurrence of fistula-in-ano in 4 cases, stricture in 3 and formation of a sinus in 3 cases. Other late complications were small bowel obstruction in one patient and pain which required removal of wire in one case $^{[27]}$. David et al., found Anal stenosis occurred in 8/24 patients (33.33\%) after sphincter repair ${ }^{[19]}$. Demirbas et. al., in his study on 44 patients found that the most common complication was bleeding, urinary infection and post-operative perianal fistula $^{[12]}$.

Amel A. Hashish in his paper for evaluation of the results of sphincter repair in perineal trauma in childrens found that the most common complications was wound disruption and wound dehiscence followed by other complications as feacal incontinence; urethral strictures and vaginal stricture ${ }^{[31]}$. To see if the method of wound closure will have any effect on the outcomes; we used two methods for closure of the wound, we found that vertical closure of the perineal wound is significantly associated with less incidence of wound disruption than closure of the lateral edge of the wound and leaving the central part, so it may be better to close the wound vertically whenever possible (Figure 6). According to our knowledge; no papers discuss this point previously. Londono et. Al. reported that the incidence of infective complications was not significantly different when non-absorbable or absorbable sutures were used ${ }^{[27]}$. Duration of symptoms before the operation in this study ranged from 0 to 60 months (mean time 22 months), some patients are too embarrassed to ask for medical help or because the symptom becomes gradually worse with progressive neuropathic change owing to aging or subsequent deliveries ${ }^{[32]}$. Duration of symptoms was not a significant factor in the outcomes after surgery in this study. Preoperative bowel preparation and prophylactic antibiotics should always be prescribed. In the immediate postoperative period impaction must be prevented by taking only clear fluids during the first week and by the prescription of laxatives. No obvious advantage could be demonstrated for the use of a covering colostomy and it Is used in cases of severe perineal trauma, this was also illustrated by other previous studies $^{[33,34]}$.

\section{Conclusion}

Sphincter repair operation is safe and feasible operation for the treatment of fecal incontinence due to different causes. About $74 \%$ of patients may achieve complete continence after surgery. Sphincter injuries due to road traffic accidents are associated with best outcomes while iatrogenic injuries have the worst outcomes. Better results are obtained with external sphincter repair versus the isolated internal sphincter repair. It seems that age and duration after surgery doesn't affect the outcomes. Most common complication are wound disruption; closure of the perineal wound is better done vertically whenever possible.

Acknowledgements The authors would like to offer their sincere thanks to all people who participated in the study.

Conflict of interest All authors declare that they have no conflict of interests.

\section{References}

1. Macmillan AK, Merrie AE, Marshall RJ, Parry BR. The prevalence of fecal incontinence in community-dwelling adults: a systematic review of the literature. Diseases of the colon \& rectum 2004; 47 (9):1341-1349

2. Bharucha AE, Zinsmeister AR, Locke GR, Schleck C, McKeon K, Melton LJ. 
Symptoms and quality of life in community women with fecal incontinence. Clinical Gastroenterology and Hepatology 2006; 4 (8):1004-1009

3. Oberwalder M, Dinnewitzer A, Baig M, Nogueras J, Weiss E, Efron J, Vernava A, Wexner S. Do internal anal sphincter defects decrease the success rate of anal sphincter repair? Techniques in coloproctology 2006; 10 (2):94-97

4. Jorge JMN, Wexner SD . Etiology and management of fecal incontinence. Diseases of the colon \& rectum 1993; 36 (1):77-97

5. Abramov Y, Sand PK, Botros SM, Gandhi S, Miller J-JR, Nickolov A, Goldberg RP. Risk factors for female anal incontinence: new insight through the Evanston-Northwestern twin sisters study. Obstetrics \& Gynecology 2005; 106 (4):726-732

6. Valsky DV ,Lipschuetz M, Bord A, Eldar I, Messing B, Hochner-Celnikier D, Lavy Y, Cohen SM, Yagel S. Fetal head circumference and length of second stage of labor are risk factors for levator ani muscle injury, diagnosed by 3-dimensional transperineal ultrasound in primiparous women. American journal of obstetrics and gynecology 2009; 201 (1):91. e91-91. e97

7. Evans C, Davis K, Kumar D. Overlapping anal sphincter repair and anterior levatorplasty: effect of patient's age and duration of follow-up. International journal of colorectal disease 2006; 21 (8):795-801

8. Young CJ, Mathur MN, Eyers AA, Solomon MJ. Successful overlapping anal sphincter repair. Diseases of the colon \& rectum 1998; 41 (3):344-349

9. Zorcolo L, Covotta L, Bartolo D. Outcome of Anterior Sphincter Repair: Comparison of Early and Late Results.2005

10. Malouf AJ, Norton CS, Engel AF, Nicholls RJ, Kamm MA. Long-term results of overlapping anterior analsphincter repair for obstetric trauma. The Lancet 2000; 355 (9200):260-265

11. Fletcher JG, Busse R, Riederer SJ, Hough D, Gluecker T, Harper C, Bharucha AE. Magnetic resonance imaging of anatomic and dynamic defects of the pelvic floor in defecatory disorders. The American journal of gastroenterology 2003; 98 (2):399-411

12. Demirbas S, Atay V, Sucullu I, Filiz AI. Overlapping repair in patients with anal sphincter injury. Medical Principles and Practice 2008; 17 (1):56-60

13. Oliveira L, Pfeifer J, Wexner S. Physiological and clinical outcome of anterior sphincteroplasty. British Journal of Surgery 1996; 83 (4):502-505

14. Simmang C, Birnbaum EH, Kodner IJ, Fry RD, Fleshman JW. Anal sphincter reconstruction in the elderly: does advancing age affect outcome? Diseases of the colon \& rectum 1994; 37 (11): 1065-1069

15. Gutierrez AB, Madoff RD, Lowry AC, Parker SC, Buie WD, Baxter NN. Longterm results of anterior sphincteroplasty. Diseases of the colon \& rectum 2004; 47 (5):727-732

16. Morren G, Hallböök O, Nyström PO, Baeten C, Sjödahl R (2001) Audit of anal-sphincter repair. Colorectal Disease 2001;3 (122-17)

17. Sitzler P, Thomson J. Overlap repair of damaged anal sphincter. Diseases of the colon \& rectum 1996;39 (12):1356-1360

18. Tjandra J, Han W, Goh J, Carey M, Dwyer P. Direct repair vs. overlapping sphincter repair. Diseases of the colon \& rectum 2003;46 (7):937-942

19. Haque PD, Mahajan A, Singh N, Kapoor R, Chaudhry NK. Managing traumatic anal sphincter injuries without the use of endo-anal ultrasound: an experience with 29 patients presenting to the surgery department at a tertiary care centre in North India. International Surgery Journal 2016;3 (2):697-700

20. Gleason JL, Markland A, Greer WJ, Szychowski JM, Gerten KA, Richter HE. Anal sphincter repair for fecal incontinence: effect on symptom severity, quality of life, and anal sphincter squeeze pressures. International urogynecology journal 2011; 22 (12): 1587-1592

21. Maslekar S, Gardiner AB, Duthie GS. Anterior anal sphincter repair for fecal incontinence: good longterm results are possible. Journal of the American College of Surgeons 2007;204 (1):40-46 
22. Fang DT, Nivatvongs S, Vermeulen FD, Herman FN, Goldberg SM, Rothenberger DA. Overlapping sphincteroplasty for acquired anal inco-ntinence. Diseases of the colon \& rectum 1984; 27 (11):720-722

23. Pezim ME, Spencer RJ, Stanhope CR, Beart RW, Ready RL, Ilstrup DM . Sphincter repair for fecal incontinence after obstetrical or iatrogenic injury. Diseases of the colon \& rectum 1987;30 (7):521-525

24. Ha HT, Fleshman JW, Smith M, Read TE, Kodner IJ, Birnbaum EH. Manometric squeeze pressure difference parallels functional outcome after overlapping sphincter reconstruction. Diseases of the colon \& rectum 2001; 44 (5):655-660

25. Rothbarth J, Bemelman W, Meijerink W, Buyze-Westerweel M, Van Dijk J, Delemarre J. Long-term results of anterior anal sphincter repair for fecal incontinence due to obstetric injury/with invited commentaries. Digestive surgery 2000; 17 (4):390-394

26. Gilliland R, Altomare DF, Moreira H, Oliveira L, Gilliland JE, Wexner SD. Pudendal neuropathy is predictive of failure following anterior overlapping sphincteroplasty. Diseases of the colon \& rectum 1998; 41 (12):1516-1522

27. Londono-Schimmer E, Garcia-Duperly R, Nicholls R, Ritchie J, Hawley P, Thomson J. Overlapping anal sphincter repair for faecal incontinence due to sphincter trauma: five year follow-up functional results. International journal of colorectal disease 1994;9 (2):110-113

28. Leroi A-M, Kamm M, Weber J, Denis P, Hawley P. Internal anal sphincter repair. International journal of colorectal disease 1997; 12 (4):243-245

29. Halverson AL, Hull TL. Long-term outcome of overlapping anal sphincter repair. Diseases of the colon \& rectum 2002;45 (3):345-348

30. Karoui S, Leroi A, Koning E, Menard J, Michot F, Denis P. Results of sphincteroplasty in 86 patients with anal incontinence. Diseases of the colon \& rectum 2000; 43 (6):813-820

31. Hashish AA. Perineal trauma in children: a standardized management approach. Annals of Pediatric Surgery 2011;7 (2):55-60

32. Enck P, Bielefeldt K, Rathmann W, Purrmann J ,Tschöpe D, Erckenbrecht JF. Epidemiology of faecal incontinence in selected patient groups. International journal of colorectal disease 1991;6 (3): $143-146$

33. Phillips R. Faecal incontinence: Treatment: anal sphincter repair. Coloproctology and the pelvic floor: pathophysiology and management 2nd Edn Butterworths-Heinemann, Oxford: 1992; 260-264

34. Scott A, Hawley P, Phillips R. Results of external sphincter repair in Crohn's disease. British journal of surgery 1998;76 (9):959-960 